DOES COMMUNICATING SAFETY MATTER?

Fatima Wang*, King's College London, UK

Carmen Lopez, University of Brighton, UK

Annals of Tourism Research

*Corresponding author 


\title{
DOES COMMUNICATING SAFETY MATTER?
}

\begin{abstract}
Tourists generally prefer to visit safe destinations. However, it is rare to see safety messages in promotional materials. Does communicating safety in destination-branding campaigns matter to tourists? We use an experimental design to explore the relationship between safety messages and visit intentions. The results show that the extent to which safety messages enhance visit intentions depends on tourists' risk propensity and self-efficacy in travel planning. Safety messages are more effective for low-risk-propensity respondents than for high-risk-propensity respondents. They are also more effective for respondents with high self-efficacy in travel planning than for those with low self-efficacy. We conclude that safety messages can help promote a destination, but cognitive tendencies moderate the relationship.
\end{abstract}

\section{KEYWORDS}

Safety, risk, self-efficacy, tourism, advertising 


\section{INTRODUCTION}

Travel-related decisions about unfamiliar places are often made under uncertainty because tourists' perceptions are based on piecemeal or incomplete information (Um \& Crompton, 1992; Williams \& Baláž, 2015). Destinations compete on perceptions (Baloglu \& Mangaloglu, 2001). Through promotional material and destination branding, tourism providers seek to attract tourists' attention and influence perceptions by highlighting differentiating factors between destinations that may be highly substitutable (Byun \& Jang, 2015; Morgan, Pritchard, \& Piggott, 2002; Qu, Kim, \& Im, 2011). Marketers' advertising efforts can induce positive place images in the minds of tourists through powerful imagery (Gunn, 1988) and guide tourists to form travel product expectations by reducing the intangibility of the future travel experience (Buhalis, 2000).

Scholars have long recognized that destination safety is important to tourism success (Pizam \& Mansfeld, 2006; Sönmez, Apostolopoulos, \& Tarlow, 1999). Perceptions of safety contribute to the quality of travel experience which is part of destination image formation (Baloglu \& McCleary, 1999). Safety perceptions can influence tourists' emotions, feelings of satisfaction, and loyalty intentions (Yüksel \& Yüksel, 2007). Nevertheless, scholars have not studied whether marketers can use safety messages in destination advertising. Despite wide recognition that safety is important to tourists and tourism development, there is little understanding of whether explicit safety messages serve as a motivator in destination selection.

The question is complicated by the debate about safety perceptions and visit intentions. On the one hand, research shows that tourists avoid destinations that appear unsafe and adjust their travel plans accordingly (Yüksel \& Yüksel, 2007). On the other hand, there is evidence that some tourists are not deterred from visiting or recommending risky destinations (George, 2010). Some tourists may paradoxically feel that destinations become safer after a terrorist attack (Wolff \& Larsen, 2014). They may purposely visit post-disaster sites as a form of "dark tourism" (Biran, Liu, Li, \& Eichhorn, 2014). They may even seek risk for a sense of excitement, as documented in the adventure tourism literature (Weber, 2001).

Williams and Baláž (2015) point out that risk and uncertainty are not exceptional but rather inherent to the tourism experience. Sönmez and Graefe (1998) present travel risk perceptions and safety concerns as parallel concepts. Perceived travel risks have been well documented (e.g., Adam, 2015; Fuchs \& Reichel, 2011) and include physical injuries from transport, activities, natural disasters, terrorism, hygiene, or equipment failure, as well as financial risks and sociopsychological risks (Roehl \& Fesenmaier, 1992; Sönmez et al., 1999; Tsaur, Tzeng, $\&$ Wang, 1997). Tourists are aware of risk and uncertainty when traveling. Therefore, the question is not about the inherent risks of travel but whether a potential visitor perceives a destination as being safe enough to visit (Karl, 2016). This, in turn, draws attention to how a destination can promote itself as a safe place to visit. Williams and Baláž (2015) call for more research to explain the variability of individual resilience to travel risk.

In the current study, we do not explore different kinds of destination risk but rather evaluate the impact of a destination's safety messages on tourists' intentions to visit. We develop and test a model of tourist reaction to safety messages in destination advertising. Using an experimental approach and drawing on categorization, risk propensity, and self-efficacy theories, we test how potential tourists view safety messages about a city called Dubrovnik and the extent to which their perceptions influence their visit intentions. Dubrovnik is a medieval seaside city in Croatia and a UNESCO world heritage site. It drew 1.8 million tourist arrivals in 2017 (Croatia Ministry of Tourism, 2017, p. 31). We hypothesize that incorporating safety messages into traditional advertising enhances tourists' willingness to 
visit Dubrovnik. Moreover, a tourist's risk propensity and self-efficacy may moderate the impact of safety messages on visit intentions.

This paper makes the following contributions to the field of tourism. First, tourism studies highlight how destinations may be perceived as risky due to crime, natural disasters, and terrorism (Brunt, Mawby, \& Hambly, 2000; Chew \& Jahari, 2014; Rittichainuwat \& Chakraborty, 2009; Sönmez et al., 1999). This body of literature shows that some tourists avoid crisis-ridden destinations while others do not. Sönmez and Graefe (1998) and Karl (2016) suggest that risk aversion is associated more with older adults and that a higher risktaking propensity is associated with a higher level of education. Nonetheless, demographic variables only partially explain individual differences. Scholars have called for more research to explain variations in individual reactions to travel risk (Williams \& Baláž, 2015). We answer this call by considering the individual, nondemographic characteristics of risk propensity and self-efficacy in analyzing the relationship between safety messages and visit intentions.

Second, studies on destination safety tend to focus on image repair following crises (e.g., Chew \& Jahari, 2014; Coaffee \& Rogers, 2008; Sönmez et al., 1999) rather than on promotion in general. Notable exceptions are Enright and Newton (2004) and Hsu, Tsai, and Wu (2009), who show that tourists rank safety as a top factor when deciding between competitive destinations in Asia. However, these two studies do not examine destination promotion. Scholars have noted that using marketing tools for destination branding has helped cities and countries appear attractive, but increasingly these strategies are not enough to create differentiation (Anholt, 2008; Berthon, Hulbert, \& Pitt, 1999). Given tourists' preference for safe travel (Enright \& Newton, 2004; Hsu et al., 2009), should policy makers pay attention to more substantive safety messages to promote destinations? Would promoting safety increase a destination's attractiveness and help it stand out from the competition? Exploring the relationship between safety messages and tourists' visit intentions has managerial significance for designing and enhancing a destination's promotional strategy.

Third, scholars tend to examine experienced visitors' revisit intentions rather than prospective visitors' first-time visit intentions. For example, several scholars have studied the rebranding of destinations that have been affected by natural disasters and terrorism and how these events influence revisit intentions (Araña \& León, 2008; Chew \& Jahari, 2014; Coaffee \& Rogers, 2008; Pizam \& Mansfeld, 2006). Repeat visitors behave differently from first-time visitors because repeat visitors can draw on prior on-site experiences to form images and make future decisions about a destination, while first-time visitors cannot (Chew \& Jahari, 2014; Fakeye \& Crompton, 1991; Fuchs \& Reichel, 2011; Sönmez \& Graefe, 1998). Although it is important to use destination communication to attract repeat visitors, prospective visitors tend to be more sensitive to marketing efforts because they do not have past experience as a reference point before traveling (Fakeye \& Crompton, 1991). Therefore, we complement previous research on safety communication by looking specifically at prospective rather than repeat visitors.

\section{SAFETY COMMUNICATION, RISK PROPENSITY, AND SELF- EFFICACY}

Safety communication has served prevention, promotional, and image repair purposes across a wide range of marketing contexts. Safety communication fulfills a prevention purpose when it is used to provide warnings about product usage safety (Zuckerman \& Chaiken, 1998) or product health risks (Hammond, 2011). It serves a promotional purpose when it helps enhance the quality perceptions of a product (Aung \& Chang, 2014; Tse, 1999) and increase 
consumers' willingness to pay higher prices (Loureiro \& Umberger, 2007). Safety communication aimed at image repair is exemplified by product recalls following product harm crises (Gao, Xie, Wang, \& Wilbur, 2015).

In tourism research, scholars have mainly investigated safety communication as an image repair mechanism after crises such as infection outbreak (Liu-Lastres, Schroeder, \& Pennington-Gray, 2018), natural disasters (Chew \& Jahari, 2014), and terrorism (Sönmez et al., 1999). Safety communication in crisis contexts is intended to assuage tourists' anxieties and repair the negative image of a destination. Coaffee and Rogers (2008) describe the rebranding efforts of UK cities through visible security presence and messages of resilience following terror attacks. They argue that these efforts led to a resurgence in business conferences and international investors, but they fail to clarify the impact on nonbusiness tourists. Avraham (2015) describes message strategies used to revive tourism following the Arab Spring uprisings - for example, downplaying the seriousness of events in tourism ads by specifying that the crisis is limited to specific areas, avoiding mentioning terrorist attacks altogether, or communicating that everything is back to normal. The objective of Avraham's (2015) study is to describe and classify different strategies that destination marketers use. The author does not test cause-effect relationships.

Prevention-related safety communication in tourism has received less debate, though it is more prevalent in certain areas such as accident prevention in adventure tourism (Buckley, 2010), personal safety (Dimanche \& Lepetic, 1999), safety signs in national parks (Saunders, Weiler, Scherrer, \& Zeppel, in press), and sun safety (Peattie, Clarke, \& Peattie, 2005). Generally speaking, research shows that tourists are prone to accidents that are preventable (Page \& Meyer, 1996) and tend to be more vulnerable than residents to crime due to lack of knowledge about the area they are visiting (Chesney-Lind \& Lind, 1986). Thus, the purpose of prevention-type safety studies is to discuss effective ways to reduce preventable accidents and increase awareness about travel risks. The purpose is not to understand tourists' decisionmaking.

Safety communication for promotional purposes remains largely unexplored in the tourism literature. What the literature shows is that tourists rank safety high among the list of factors that drive their destination choice: in an empirical study, Enright and Newton (2004) find that among factors that influence the competitiveness of Hong Kong as a destination within the Asia-Pacific region, safety is the most important. Hsu et al. (2009) present a survey of Taiwan tourists and show that safety is the second most important factor for tourists visiting Taiwan. Neither of these studies addresses safety communication. Instead, they are limited to surveying tourists' criteria in choosing destinations.

We draw on categorization theory (Rosch, 1978) as the foundation for our study. Categorization is a cognitive bias theory that highlights the subjectivity of information processing and decision-making. The theory is based on the premise that human beings are unable to assimilate all the information around them. As a result, they simplify reality by selecting information and grouping it into categories. Individuals tend to resort to categorization to make decisions, especially when information is incomplete (Palich \& Bagby, 1995), which is often the case for new destinations.

Extant tourism studies have reflected the premises of categorization theory. Moutinho (1987) suggests that tourists form perceptions of destinations through the meaningful selection, organization, and interpretation of stimuli. Tourists may have a more or less positive view about how safe a destination is depending on how they categorize the stimuli. Um and Crompton (1992) argue that for unfamiliar destinations, information tends to be incomplete, and tourists will attempt to categorize different pieces of symbolic information from the media or their social group to form opinions. In an investigation of tourists' vacation- 
planning activities on the Internet, Pan and Fesenmaier (2006) argue that tourists plan their travel using episodes (e.g., destinations, activities, accommodations). Episodes serve as manageable categories that individuals make decisions about. As such, episodes are also an example of categorization.

A key tenet of categorization theory is that decisions depend on how individuals categorize information. For example, some people may categorize information as an opportunity, while others may see it as a threat, and this can lead to either taking action or avoiding the decision (Dutton \& Jackson, 1987). Certain aspects of travel may take priority over others depending on personal preferences and characteristics. Categorization highlights variations in decisionmaking and provides a basis for explaining why some tourists are not deterred from visiting unsafe places while others are. Brunt et al. (2000) argue that safety risks do not automatically translate into fear or concerns that would stop tourists from visiting a place. In other words, not all tourists categorize safety risks as threats.

Risk propensity is an individual's tolerance for risk. Risk propensity can influence how different tourists categorize the probability of travel risks differently. Seabra, Dolnicar, Abrantes, and Kastenholz (2013) highlight the heterogeneity of tourists by segmenting them into clusters based on their perceptions of risk and personal demographics, including nationality. Law (2006) shows that for the same destination (Hong Kong), tourists from different countries perceive the probability of various risks differently. Differences in risk tolerance have been explained by sociodemographic factors such as age, gender, and education, with younger, male, and more highly educated tourists tending to have a higher risk tolerance (Karl, 2016; Pizam et al., 2004; Williams \& Baláž, 2013).

Depending on an individual's risk propensity, risk can be cognitively categorized as either an inhibitor or a motivator of leisure-related decisions. Wolff and Larsen (2014) discover that the negative impact of a terrorist event on tourists' risk perceptions exists, but it may be lower for destinations that do not have a history of attacks or violence, as tourists categorize such destinations as being relatively safe. Hyde and Lawson (2003) argue that the apparent irrationality in travel decisions occurs when tourists are open to risks and want to experience the unplanned. Overall, tourism literature suggests that risk propensity is contingent on the individual and the way the individual categorizes risk in different situations. Therefore, it is important to consider risk propensity when exploring why tourists react to destination safety messages differently.

Self-efficacy is a cognitive trait that explains variations in motivation and decision making. Self-efficacy has been defined as "beliefs in one's capabilities to organize and execute the courses of action required to produce given attainments" (Bandura, 1977, p. 3). Self-efficacy describes individuals' self-regulatory bias to undertake tasks that they perceive to have control over rather than uncontrollable outcomes (Bandura, 1989; Bandura, Barbaranelli, Caprara, \& Pastorelli, 2001; Betz \& Hackett, 1986). Self-efficacy is a personal judgment about one's own ability to complete a task successfully and achieve the expected outcome.

Low self-efficacy undermines the opportunity to achieve the desired outcome either due to a lack of confidence in one's ability to complete a task or a lack of motivation to make the necessary effort to deal with the task, despite having the ability to do so (Gist \& Mitchell, 1992). In contrast, individuals with high self-efficacy are more motivated to complete a task and overcome problems in the process (Bandura, 1989). For example, individuals with high self-efficacy in information systems security would comply with an organization's security policy about changing passwords regularly, refraining from visiting suspicious websites, or storing sensitive information on their computers (Ifinedo, 2012). The level of motivation driving self-efficacy is determined not only by the task at hand but also by learnings from 
past experiences and by positive or negative emotions toward the task (Bandura \& Adams, 1977; Gist \& Mitchell, 1992).

Within the tourism literature, self-efficacy theory has formed the basis of studies on service providers, residents in tourist destinations, and tourists. Self-efficacy has been applied to service providers in terms of creative self-efficacy (Jaiswal \& Dhar, 2015; C.-J. Wang, Tsai, \& Tsai, 2014) and entrepreneurial self-efficacy (Hallak, Assaker, \& Lee, 2015; Hallak, Brown, \& Lindsay, 2012). Self-efficacy has also been studied in terms of residents' perceived control over the changes brought about by tourism development (Wang \& Xu, 2015).

Tourists' self-efficacy has been explored in a variety of contexts. In alternative tourism, McGehee (2002) describes how participation in paid Earthwatch expeditions (e.g., a trip to understand the condition of a coral reef) increases participants' sense of self-efficacy with respect to environmental change. In a postcrisis context, Liu, Schroeder, Pennington-Gray, and Farajat (2016) classify U.S. tourists who travel to Jordan into "risk perception attitude" clusters using a perceived risk and efficacy beliefs matrix. Efficacy beliefs include both selfefficacy and response efficacy toward preventive actions. The authors show that safety perceptions of Jordan mediate the relationship between risk perception attitude and travel intention.

In the context of social media, Wang and Fesenmaier (2003) apply self-efficacy to study the extent to which an individual believes that his or her contributions will affect the online travel community. High-self-efficacy contributors possess a sense of control with respect to their ability to influence opinions and travel choices in the online travel community. The results show that high self-efficacy leads to more contributions to online travel communities. From a travel-planning perspective, Hung and Petrick (2012) refer to self-efficacy as the extent to which tourists are confident in their abilities to search for information, plan ahead, and choose a destination. The authors find that high self-efficacy in tourists decreases the impact of travel constraints on constraints negotiation. In a similar vein, Yoo, Goo, Huang, Nam, and Woo (2017) study self-efficacy in the use of smart tourism technologies. They define (p. 34) self-efficacy as "tourists' perceived ability and skills of using [smart tourism technologies] to make travel plans and decisions." Drawing on the elaboration likelihood model, the authors show that high self-efficacy has a positive moderating impact on the central processing route and a negative impact on peripheral processing routes.

Overall, self-efficacy is a well-established and widely applied concept. From a categorization theory perspective, self-efficacy explains why different people may categorize similar tasks as either overwhelming or manageable. Our study considers a new destination in a previsit context. Consequently, we focus on travel-planning self-efficacy (Hung \& Petrick, 2012) that is, tourists' perceived ability and skills to make travel plans and prepare for eventualities.

\section{Hypotheses}

Tourists' perceptions of destination safety and visit intentions have been studied in relation to risk perceptions. Researchers have investigated the negative impact of terrorist attacks on destination image and attractiveness and have reaffirmed that terrorism might influence previsit decisions negatively, such that tourists react by deferring the visit or choosing a safer alternative (Araña \& León, 2008; Pizam \& Mansfeld, 2006). George (2003) suggests that tourists who feel unsafe or threatened are likely to avoid a destination altogether. For example, the Bali bombings in October 2002 had an immediate effect on visitor numbers from Australia, with many tourists claiming that they would be unlikely to visit again or recommend others to visit. (Henderson, 2003). Sönmez et al. (1999) emphasize that due to the intangible nature of tourism, positive images are crucial. The media can create a positive 
or negative destination image almost instantly, through the widespread coverage of key events. Media reports of terrorism, in particular, can easily damage a destination's positive image. At the same time, Coaffee and Rogers (2008) argue that it is possible to rebrand an area with a negative safety image, implying that marketing tools can be effective in changing destination perceptions.

Prospective first-time visitors rely more on marketing efforts to make destination decisions because they have no past experience of the destination (Fakeye \& Crompton, 1991). However, promotional materials are problematic insofar as they present limited information about destinations. Categorization theory suggests that when information is incomplete, individuals will try to simplify the decision-making process by categorizing the available information (Palich \& Bagby, 1995). Safety is a double-edged sword because it can have both positive and negative connotations. Safety taken at face value implies being safe (positive), but the concept also suggests the presence of risk (negative). The same safety message may have opposing meanings for different people, according to categorization theory. For example, when seeing a safety message, one person may conclude that the place is safe, while another may think it is a warning sign to take precautions. Nevertheless, because the word "safety" has connotations that are more positive than negative, we hypothesize that people will categorize safety messages positively and that this will lead to a greater willingness to visit the destination. Formally,

H1: The inclusion of safety messages in promoting a destination has a positive impact on visit intentions.

We argue that individuals' level of risk propensity can moderate the impact that safety messages have on travel intentions. Low risk propensity suggests a lower risk tolerance. We expect low-risk-propensity tourists to exercise greater caution and select safe destinations as a rule. Low-risk-propensity tourists are likely to be more sensitive to destination safety messages than high-risk-propensity tourists. Seeing safety messages is likely to reassure lowrisk-propensity tourists and encourage them to visit the destination. Thus, we expect low risk propensity to strengthen the relationship between safety messages and visit intentions. In addition, research on tourist skepticism indicates that tourists, in general, are more skeptical about subjective claims than objective claims, as well as to claims that relate to tourist experience rather than to product attributes (Ford, Smith, \& Swasy, 1990). Safety messages, in our experiment, are portrayed as objective destination attribute claims and should be less prone to skepticism.

High-risk-propensity tourists are more optimistic and open to risks. We argue that high-riskpropensity tourists need less reassurance. Thus, they might be less sensitive to safety messages. High-risk-propensity tourists often have a heightened awareness of risk, which encourages them to take further risk. For example, Celsi, Rose, and Leigh (1993) explain that high-risk-propensity tourists seek to increase their level of risk through repeated consumption of high-risk experiences, such as skydiving. The authors refer to this behavior as a process of "risk acculturation." High risk propensity may or may not be related to sensation seeking (Lepp \& Gibson, 2008). For instance, individuals who forego safety by not wearing a helmet or who are willing to take risks to publicly challenge a decision are also considered to have a high risk propensity (Nicholson, Soane, Fenton-O'Creevy, \& Willman, 2005). High-riskpropensity tourists tend to be more optimistic about their own safety given their higher risk tolerance. Consequently, we expect safety messages to have less of an impact on travel intentions for high-risk propensity tourists than for low-risk-propensity tourists. We hypothesize the following:

H2: The impact of safety messages on visit intentions is stronger for low-riskpropensity tourists than for high-risk-propensity tourists. 
High-self-efficacy individuals tend to be enthusiastic and persevere in finding solutions because they believe in themselves and in their ability to achieve a positive outcome (Bandura et al., 2001). In relation to travel planning, high-self-efficacy tourists feel competent about planning trips. They possess a strong conviction in their ability to assess travel information and are more likely to act upon the safety messages. High-self-efficacy tourists are unlikely to spend time construing negative scenarios in their minds. Moreover, they believe that they can deal with eventualities through preparation, and part of their process would be to seek safety information before deciding to visit a destination. Therefore, high-self-efficacy tourists should be more sensitive to safety messages than low-self-efficacy tourists. We expect high self-efficacy to strengthen the positive impact of safety messages on visit intentions.

Low-self-efficacy tourists feel less competent in the task of travel planning and are likely to become anxious about making decisions. They distrust their ability to plan ahead using the information available. Low-self-efficacy individuals are not confident about their coping capabilities and may be reluctant to prepare for eventualities. Low-self-efficacy tourists are prone to negativity (Bandura et al., 2001) and may categorize safety messages as unhelpful. They may not trust their own judgment enough to decide to visit a destination simply based on a promotional ad. They are likely to adopt a wait-and-see attitude and rely on others to decide for them (Bishop \& Barber, 2012) due to the lack of either confidence in assessing safety messages or motivation to make a decision (Gist \& Mitchell, 1992). Tourism scholars have previously highlighted that some tourists tend to worry in any given situation and that their anxiety may reduce their willingness to travel, even if threats are minimal (Larsen, Brun, \& Øgaard, 2009). Consequently, we expect low self-efficacy to attenuate the positive impact of safety messages on travel intentions.

H3: The impact of safety messages on visit intentions is stronger for tourists with high self-efficacy in travel planning than for tourists with low self-efficacy in travel planning.

\section{Methodology}

The study used an experimental design with data collected in May 2018 from an online panel in the United States. Although destination promotion can occur through different media, we chose print advertising because it is easier to manipulate. The between-subjects factor was the type of message in the advertisement (no safety message vs. safety messages). Respondents were randomly assigned to one of the two groups. Those assigned to the control group viewed an advertisement for a destination without any safety messages (see the ad in Appendix A). For the treatment group, an advertisement with safety messages served as the safety communication manipulation (see the ad in Appendix A). All respondents saw an ad for at least ten seconds before moving to the online survey. The survey included questions about visit intention based on the ad and questions about risk propensity, self-efficacy, and frequency of traveling abroad. This was followed by demographic questions.

Destination and tourist sample. We selected Dubrovnik as the destination and the United States for our respondent sample to reduce bias related to travel intentions. Dubrovnik is geographically distant from the United States and not easily reached. In 2017, U.S. tourists accounted for only $2.8 \%$ of all foreign tourism in Dubrovnik and $1.5 \%$ of overnight tourists (Croatia Ministry of Tourism, 2017, p. 26). Dubrovnik is much less prominent than European cities such as Paris or London and is less known by U.S. residents. Thus, respondents may have fewer preconceptions or feelings about the Dubrovnik as a travel destination. We further ensured that past experience would not influence the responses by targeting only respondents 
who have never visited Dubrovnik before. We screened respondents with several filter questions.

We drew our sample from one country to reduce cultural bias in risk perception (Law, 2006; Seabra et al., 2013). We selected U.S. tourists for our study because the United States represents the second highest percentage of tourism departures worldwide, behind China (World Tourism Organization, 2018). Although China is the leader in international tourism departures, we chose the United States based on research showing that tourists from the United States, Hong Kong, and Australia are more perceptive to travel risk and place more importance on feeling safe than tourists from the United Kingdom, Canada, and Greece (Reisinger \& Mavondo, 2006). Tourists from the United States, Hong Kong, and Australia are more anxious and reluctant to travel than tourists from the United Kingdom, Canada, and Greece (idem). It is possible that Chinese tourists are similar to the U.S., Hong Kong, and Australia in terms of travel risk perceptions, but we could not ascertain this as no similar study is available for China.

The U.S. population's general sensitivity to travel risk and safety highlights the potential for using the United States as our target country. We include different age groups to provide variability in our study, as scholars have shown that the importance of perceived safety in destination decisions increases as tourists grow older (Lindqvist \& Björk, 2000). In total, 312 U.S. respondents, all aged 18 years and older, who had never traveled to Dubrovnik participated in the study. The response rate was $38.57 \%$.

Measures. We operationalized visit intention using the seven-point Likert scale ( 1 = "strongly disagree"; 7 = "strongly agree") from Zeugner-Roth and Žabkar (2015). We measured risk propensity using items on recreational, safety, and social risks from Nicholson et al. (2005). Respondents rated how frequently they took recreational, safety, and social risks in their everyday lives on a seven-point rating scale ( 1 = "never"; 7 = "very frequently"). Following Loucks-Atkinson and Mannell (2007) and Hung and Petrick (2012), we evaluated selfefficacy by asking respondents to rate their level of confidence in coping with 12 travelrelated constraints on a seven-point rating scale ( 1 = "not confident at all"; 7 = "extremely confident"). Demographic factors, such as gender, age, education, and income, influence tourists' motivation for travel (Williams \& Baláž, 2013), so we included them as control variables. According to Lepp and Gibson (2003), travel experience leads tourists to downplay travel risks. Consequently, we also included frequency of traveling abroad as a control variable, measured using a single item on a seven-point rating scale ( $1=$ "never"; 7 = "very frequently"). Appendix B shows the individual items for each construct.

Model validation. We validated the multi-item measures (visit intention, risk propensity, and self-efficacy) with confirmatory factor analysis using MPlus8 (Muthén and Muthén, 19982017). We examined convergent validity and then discriminant validity of the measures using Fornell and Larcker's (1981) test. The purified measures displayed good Cronbach's alpha reliability (intention to visit: $\alpha=.902$; risk propensity: $\alpha=.714$; self-efficacy: $\alpha=.939$ ). Following Hu and Bentler's (1999) advised cutoff values, we found that the purified complete measurement model showed a good fit $\left(\chi^{2}=222.420\right.$, d.f. $=132, p=.000$; comparative fit index $=.966$; Tucker-Lewis fit index $=.961$; root mean square error of approximation $=.047$; standardized root mean square residual $=.040$ ).

\section{Results}

Appendix B shows the means, standard deviations, skew, and kurtosis for the survey items. The profile of the sample is as follows: the average age of respondents is 45 years, $62 \%$ of respondents are female, and $49 \%$ have a college/associate's degree or a bachelor's degree. 
Manipulation check. We performed an analysis of variance (using bootstrapping) for the manipulation check of the perceived safety of Dubrovnik as a tourist destination after seeing the ad. We measured perceived safety using a single-item, seven-point rating scale. As we expected, the control group, which did not see any safety message, exhibited lower scores on safety than the safety group, and this difference was significant $\left(M_{\text {Control }}=3.97\right.$ vs. $M_{\text {group2 }}=$ $4.44) ; F(1,311)=9.09, p<.01)$.

Main effect and moderating effect. We ran an analysis of covariance to test the direct impact of the presence or absence of the safety message on the intention to visit the city. An analysis of covariance provides the tools to analyze experimental data and enables more sensitive tests of treatment effects (Hair et al., 2014). We included the frequency of traveling abroad and demographics (age, gender, income, and education) as covariates. To test the moderating effect of risk propensity, we used a median split to classify respondents as high risk propensity and low risk propensity. We used the same procedure to test the moderating effect of self-efficacy and classify participants as high self-efficacy and low self-efficacy. The resulting mean composite risk propensity scores are significantly different between the two groups $\left(M_{\mathrm{HR}}=\right.$ $\left.3.906, S D=0.952 ; M_{\mathrm{LR}}=1.770, S D=0.634 ; p<.001\right)$. Similarly, the mean composite scores of the two groups are significantly different for self-efficacy $\left(M_{\mathrm{HSE}}=5.767, S D=0.611 ; M_{\mathrm{LSE}}\right.$ $=3.786, S D=0.857 ; p<.05)$. We then included the interaction terms between risk propensity and main effect (safety message vs. no safety message) and between self-efficacy and the main effect in the model.

The results (see Table 1) reveal significant differences between the no-safety-message condition and the safety-message condition for intention to visit the destination $(F(1,301)=$ $9.166, p=.003)$. These results support H1.

\section{[Insert Table 1 about here]}

Furthermore, the results reveal a significant interaction effect between risk propensity and the presence of the safety message on intention to visit $(F(1,301)=4.115, p=.043)$ and a marginally significant interaction effect between self-efficacy and the presence of the safety message on intention to visit $(F(1,301)=3.222, p=.074)$. As Fig.1 shows, when high-riskpropensity respondents were exposed to an advertisement with safety messages, their intention to visit Dubrovnik increased. However, when low-risk-propensity respondents were exposed to the same safety messages, their willingness to visit the city increased even further. We hypothesized that this would be the case $(\mathrm{H} 2)$ because low-risk-propensity respondents would be looking for low-risk (i.e., safer) destinations.

Fig. 2 shows that the intention to visit Dubrovnik is greater for high-self-efficacy respondents than for low-self-efficacy respondents after they processed the advertisement with the safety messages. This result supports H3. Low-self-efficacy individuals have little confidence in their ability to cope with travel planning and tend not to make travel decisions on their own. Thus, low self-efficacy limits the impact of safety messages on visit intentions.

[Insert Figure 1 and Figure 2 about here]

\section{CONCLUSION}

This paper contributes to research on destination image, destination risk, and safety communication in tourism. We distinguish different types of safety communication (preventive, repair, and promotional) and identify an important research gap — namely, 
tourism research has not given sufficient attention to promotional safety communication. Drawing on categorization, self-efficacy, and risk theories, our study shows that safety messages have a positive effect on visit intention. However, the effectiveness of safety messages depends on individual cognition and the way information is categorized. Low-selfefficacy individuals categorize safety messages as information that they cannot assess confidently. Therefore, they lack the motivation to act upon these messages. Our study shows that low self-efficacy reduces the positive effect of safety messages on visit intentions. High risk propensity also mollifies the impact of safety messages because safety is categorized as a low-priority criterion among those with a high risk tolerance.

By showing that safety communication can be used for promotional purposes, our study complements tourism research that has examined safety communication from image repair or prevention perspectives. The results supplement tourism studies that underscore the role of safety perceptions on risk attitudes and visit intentions (Liu et al., 2016), the heterogeneity of tourists' risk perceptions (Law, 2006; Seabra et al., 2013), the importance of self-efficacy in tourists' information processing and decision-making (Yoo et al., 2017), and the utility of destination branding for reducing tourists' risk perceptions (Berthon et al., 1999). Although these studies show that individual reactions to destination risk and safety differ, they do not explore the reasons behind individual variations (Williams \& Baláž, 2015). Thus, our contribution is to offer evidence that safety messages can increase visit intentions in the previsit context and that risk propensity and self-efficacy are factors that explain individual variations and moderate this relationship.

Should safety communication be included in destination promotional efforts? The primary goal of destination promotion is to make a destination more attractive to potential visitors. Safety messages can help destinations achieve this goal. Incorporating messages about destination safety in promotional material may seem impractical at first glance. Safety information is not traditionally used as promotional material, and marketers may not have the evidence needed to make safety claims. Thus, it is likely that a policy initiative is required. Policy makers often invest in image repair after major crises (Avraham, 2015; Coaffee \& Rogers, 2008). The insights from our study provide a starting point for discussing safety measures outside a crisis context. Policy makers often implement safety measures without necessarily promoting them to the public or treating them as a factor that may attract tourists to a destination. They may consider incorporating safety communication to supplement existing tourism marketing efforts.

Destination images, developed as part of the promotional effort to attract tourists, should be targeted to the right audience (Fakeye \& Crompton, 1991). With big data and tourist analytics, it is becoming easier to profile tourists. Thus, safety communication strategies would ideally be contingent on tourists' characteristics. The results of our study imply that safety communication is more effective for low-risk-propensity tourists and those with high self-efficacy in travel planning. Such tourists welcome safety signals because they are risk averse, they possess a strong conviction in their travel planning abilities, and they rely on information to make travel decisions. For these tourists, safety communication should focus on information quality (Yoo et al., 2017) and use cognitive language (Byun \& Jang, 2015).

Indeed, Yoo et al. (2017) suggest that when targeting tourists with high self-efficacy in smart technologies, a marketer's focus should be on information quality, as it encourages cognitive processing of information through the central route and leads to travel decision support satisfaction. Although Yoo et al. (2017) study self-efficacy in smart technologies, a parallel can be drawn with travel-planning self-efficacy because both involve extensive information search for decision-making. Moreover, Byun and Jang (2015) show that advertising messages are effective in promoting destinations when cognitive language is used to showcase 
utilitarian destinations and when affective language is used for hedonic destinations. Cognitive language would be more suitable to increase information quality.

Safety messages appear to be least effective for high-risk-propensity and low-self-efficacy tourists. For the former, risk is not an issue, or for the latter, there is a reluctance to act upon the safety information due to a general lack of confidence. Yoo et al. (2017) suggest that focusing on peripheral aspects of the technologies, such as interface design and visibility in search engines, can lead to higher satisfaction for tourists with low self-efficacy in smart technologies. Applying their findings to our study, marketers might target high-riskpropensity tourists and low-self-efficacy tourists by communicating safety indirectly through imagery, links to further information about safety, and affective language. In addition, firsttime visitors tend to rely more on travel agents than repeat visitors (Fuchs \& Reichel, 2011). Travel agents play a crucial role with low-self-efficacy customers regarding the issue of safety and fostering travel decisions.

Our study is not without limitations. First, we focus on an isolated decision about a single destination - in particular, a seaside destination in a developed country. Although this decision limits bias in the experiment, it raises the question as to whether the results would apply to other destinations (e.g., large cities, remote areas, less developed countries). Moreover, tourists do not usually make travel decisions in isolation. Future research could investigate how safety messages influence the choice between alternative locations and between different types of locations.

Second, we did not test our propositions for repeat visitors, who tend to focus on different types of risks (Fuchs \& Reichel, 2011) and are less reliant on promotional images than firsttime visitors (Fakeye \& Crompton, 1991). Our study may not be generalizable to repeat visitors, who gain knowledge about a destination's safety through personal experience.

Third, our study is confined to individual U.S. tourists. The percentage of females in the panel is also slightly higher than that in the target population. Extending the range of countries may reveal location-specific issues and potential cultural differences (Seabra et al., 2013). There is also potential to explore differences in how individuals, families, and travel groups respond to safety messages.

Fourth, we do not explore the differences in using print and digital formats or compare various forms of media communication. In addition, the safety advertisement we presented to the treatment group contained more information and was longer than the control group advertisement. The length of the ad might have increased the attractiveness of the destination. Previous research suggests that lengthier advertisement copy can be used as a heuristic to infer how good the brand/product is and how honest the advertiser is (Franke, Huhmann, \& Mothersbaugh, 2004; Ogilvy, 2013), thus increasing the attractiveness of the brand/product/advertiser. Furthermore, the safety advertisement refers to Croatia as an awardwinning destination, unlike the control advertisement.

Fifth, our study evaluates the main effect of one factor with two conditions: the presence or absence of the safety message. A more elaborate experimental design with additional independent variables and conditions might provide a more detailed description of the changes in the intention to visit a destination.

In conclusion, using safety messages to promote a destination matters for prospective visitors. Our study reveals that safety messages have a positive impact on visit intentions. However, self-efficacy and risk propensity moderate in this relationship. Safety has become a paramount issue in today's world and will continue to be a challenge in the years ahead. Thus, marketers and policy makers should make efforts to understand its significance for tourists. We hope that our study provides a platform for further theory development on the importance of safety communication in the promotion of tourist destinations. 


\section{REFERENCES}

Adam, I. (2015). Backpackers' risk perceptions and risk reduction strategies in Ghana. Tourism Management, 49, 99-108.

Anholt, S. (2008). Place branding: Is it marketing, or isn't it? Place Branding and Public Diplomacy, $4(1), 1$.

Araña, J. E., \& León, C. J. (2008). The impact of terrorism on tourism demand. Annals of Tourism Research, 35(2), 299-315.

Aung, M. M., \& Chang, Y. S. (2014). Traceability in a food supply chain: Safety and quality perspectives. Food Control, 39, 172-184.

Avraham, E. (2015). Destination image repair during crisis: Attracting tourism during the Arab Spring uprisings. Tourism Management, 47(Supplement C), 224-232.

Baloglu, S., \& Mangaloglu, M. (2001). Tourism destination images of Turkey, Egypt, Greece, and Italy as perceived by U.S.-based tour operators and travel agents. Tourism Management, 22(1), 19.

Baloglu, S., \& McCleary, K. W. (1999). A model of destination image formation. Annals of Tourism Research, 26(4), 868-897.

Bandura, A. (1977). Self-efficacy: toward a unifying theory of behavioral change. Psychological Review, 84(2), 191.

Bandura, A. (1989). Regulation of cognitive processes through perceived self-efficacy. Developmental Psychology, 25(5), 729.

Bandura, A., \& Adams, N. E. (1977). Analysis of self-efficacy theory of behavioral change. Cognitive Therapy and Research, 1(4), 287-310.

Bandura, A., Barbaranelli, C., Caprara, G. V., \& Pastorelli, C. (2001). Self-efficacy beliefs as shapers of children's aspirations and career trajectories. Child development, 72(1), 187-206.

Berthon, P., Hulbert, J. M., \& Pitt, L. F. (1999). Brand management prognostications. Sloan Management Review, 40(2), 53.

Betz, N. E., \& Hackett, G. (1986). Applications of self-efficacy theory to understanding career choice behavior. Journal of Social and Clinical Psychology, 4(3), 279-289.

Biran, A., Liu, W., Li, G., \& Eichhorn, V. (2014). Consuming post-disaster destinations: The case of Sichuan, China. Annals of Tourism Research, 47, 1-17.

Bishop, M., \& Barber, N. (2012). A market segmentation approach to esteem and efficacy in information search. Journal of Consumer Marketing, 29(1), 13-21.

Brunt, P., Mawby, R., \& Hambly, Z. (2000). Tourist victimisation and the fear of crime on holiday. Tourism Management, 21(4), 417-424.

Buckley, R. (2010). Communications in adventure tour products: Health and safety in rafting and kayaking. Annals of Tourism Research, 37(2), 315-332.

Buhalis, D. (2000). Marketing the competitive destination of the future. Tourism Management, 21(1), 97-116.

Byun, J., \& Jang, S. (2015). Effective destination advertising: Matching effect between advertising language and destination type. Tourism Management, 50(Supplement C), 31-40.

Celsi, R. L., Rose, R. L., \& Leigh, T. W. (1993). An exploration of high-risk leisure consumption through skydiving. Journal of Consumer Research, 20(1), 1-23.

Chesney-Lind, M., \& Lind, I. Y. (1986). Visitors as victims crimes against tourists in Hawaii. Annals of Tourism Research, 13(2), 167-191.

Chew, E. Y. T., \& Jahari, S. A. (2014). Destination image as a mediator between perceived risks and revisit intention: A case of post-disaster Japan. Tourism Management, 40, 382-393.

Coaffee, J., \& Rogers, P. (2008). Reputational risk and resiliency: The branding of security in placemaking. Place Branding and Public Diplomacy, 4(3), 205-217. 
Croatia Ministry of Tourism. (2017). Tourism in figures 2017. Retrieved 7/10/2018: https://www.htz.hr/sites/default/files/2018-08/HTZ\%20TUB\%20ENG 2017\%20FINAL.pdf

Dimanche, F., \& Lepetic, A. (1999). New Orleans tourism and crime: A case study. Journal of Travel Research, 38(1), 19-23.

Dutton, J. E., \& Jackson, S. E. (1987). Categorizing strategic issues: Links to organizational action. Academy of Management Review, 12(1), 76-90.

Enright, M. J., \& Newton, J. (2004). Tourism destination competitiveness: a quantitative approach. Tourism Management, 25(6), 777-788.

Fakeye, P. C., \& Crompton, J. L. (1991). Image differences between prospective, first-time, and repeat visitors to the lower Rio Grande valley. Journal of Travel Research, 30(2), 10-16.

Ford, G. T., Smith, D. B., \& Swasy, J. L. (1990). Consumer skepticism of advertising claims: Testing hypotheses from economics of information. Journal of Consumer Research, 16(4), 433-441.

Fornell, C., \& Larcker, F. (1981). Evaluating Structural Equation Models with Unobserved Variables and Measurement Error. Journal of Marketing Research, 28 (February), 39-50.

Franke, G. R., Huhmann, B. A., \& Mothersbaugh, D. L. (2004). Information content and consumer readership of print ads: a comparison of search and experience products. Journal of the Academy of Marketing Science, 32(1), 20-31.

Fuchs, G., \& Reichel, A. (2011). An exploratory inquiry into destination risk perceptions and risk reduction strategies of first time vs. repeat visitors to a highly volatile destination. Tourism Management, 32(2), 266-276.

Gao, H., Xie, J., Wang, Q., \& Wilbur, K. C. (2015). Should ad spending increase or decrease before a recall announcement? The marketing-finance interface in product-harm crisis management. Journal of Marketing, 79(5), 80-99.

George, R. (2003). Tourist's perceptions of safety and security while visiting Cape Town. Tourism Management, 24(5), 575-585.

George, R. (2010). Visitor perceptions of crime-safety and attitudes towards risk: The case of Table Mountain National Park, Cape Town. Tourism Management, 31(6), 806-815.

Gist, M. E., \& Mitchell, T. R. (1992). Self-efficacy: A theoretical analysis of its determinants and malleability. Academy of Management Review, 17(2), 183-211.

Gunn, C. A. (1988). Vacationscape: Designing tourist regions: Van Nostrand Reinhold.

Hair, J. F., Black, W. C., Babin, B. J., and Anderson, R. E. (2014) Multivariate Data Analysis. $7^{\text {th }}$ ed. Harlow: Pearson Education.

Hallak, R., Assaker, G., \& Lee, C. (2015). Tourism entrepreneurship performance: The effects of place identity, self-efficacy, and gender. Journal of Travel Research, 54(1), 36-51.

Hallak, R., Brown, G., \& Lindsay, N. J. (2012). The place identity-performance relationship among tourism entrepreneurs: A structural equation modelling analysis. Tourism Management, 33(1), 143-154.

Hammond, D. (2011). Health warning messages on tobacco products: a review. Tobacco control, 20(5), 327-337.

Henderson, J. C. (2003). Terrorism and tourism. Journal of Travel \& Tourism Marketing, 15(1), 41-58.

Hsu, T.-K., Tsai, Y.-F., \& Wu, H.-H. (2009). The preference analysis for tourist choice of destination: A case study of Taiwan. Tourism Management, 30(2), 288-297.

Hu, L-T., \& Bentler, P-M. (1999). Cutoff Criteria for Fit Indexes in Covariance Structure Analysis: Conventional Criteria Versus New Alternatives. Structural Equation Modeling, 6, 1-55.

Hung, K., \& Petrick, J. F. (2012). Testing the effects of congruity, travel constraints, and self-efficacy on travel intentions: An alternative decision-making model. Tourism Management, 33(4), 855-867.

Hyde, K. F., \& Lawson, R. (2003). The nature of independent travel. Journal of Travel Research, 42(1), 13-23. 
Ifinedo, P. (2012). Understanding information systems security policy compliance: An integration of the theory of planned behavior and the protection motivation theory. Computers \& Security, 31(1), 83-95.

Jaiswal, N. K., \& Dhar, R. L. (2015). Transformational leadership, innovation climate, creative selfefficacy and employee creativity: A multilevel study. International Journal of Hospitality Management, 51, 30-41.

Karl, M. (2016). Risk and uncertainty in travel decision-making. Journal of Travel Research, 57(1), 129-146.

Larsen, S., Brun, W., \& Øgaard, T. (2009). What tourists worry about - Construction of a scale measuring tourist worries. Tourism Management, 30(2), 260-265.

Law, R. (2006). The perceived impact of risks on travel decisions. International Journal of Tourism Research, 8(4), 289-300.

Lepp, A., \& Gibson, H. (2003). Tourist roles, perceived risk and international tourism. Annals of Tourism Research, 30(3), 606-624.

Lepp, A., \& Gibson, H. (2008). Sensation seeking and tourism: Tourist role, perception of risk and destination choice. Tourism Management, 29(4), 740-750.

Lindqvist, L.-J., \& Björk, P. (2000). Perceived safety as an important quality dimension among senior tourists. Tourism Economics, 6(2), 151-158.

Liu-Lastres, B., Schroeder, A., \& Pennington-Gray, L. (2018). Cruise line customers' responses to risk and crisis communication messages: An application of the risk perception attitude framework. Journal of Travel Research, 0047287518778148.

Liu, B., Schroeder, A., Pennington-Gray, L., \& Farajat, S. A. D. (2016). Source market perceptions: How risky is Jordan to travel to? Journal of Destination Marketing \& Management, 5(4), 294304.

Loucks-Atkinson, A., \& Mannell, R. C. (2007). Role of self-efficacy in the constraints negotiation process: The case of individuals with fibromyalgia syndrome. Leisure Sciences, 29(1), 19-36.

Loureiro, M. L., \& Umberger, W. J. (2007). A choice experiment model for beef: What US consumer responses tell us about relative preferences for food safety, country-of-origin labeling and traceability. Food Policy, 32(4), 496-514.

McGehee, N. G. (2002). Alternative tourism and social movements. Annals of Tourism Research, 29(1), 124-143.

Morgan, N., Pritchard, A., \& Piggott, R. (2002). New Zealand, 100\% pure. The creation of a powerful niche destination brand. The Journal of Brand Management, 9(4), 335-354.

Moutinho, L. (1987). Consumer Behaviour in Tourism. European Journal of Marketing, 21(10), 5-44.

Muthén, L.K., \& Muthén, B.O. (1998-2017), MPlus User's Guide. $8^{\text {th }}$ edn. Los Angeles, CA: Muthén and Muthén.

Nicholson, N., Soane, E., Fenton-O'Creevy, M., \& Willman, P. (2005). Personality and domain-specific risk taking. Journal of Risk Research, 8(2), 157-176.

Ogilvy, D. (2013). Ogilvy on advertising: Vintage.

Page, S. J., \& Meyer, D. (1996). Tourist accidents: An exploratory analysis. Annals of Tourism Research, 23(3), 666-690.

Palich, L. E., \& Bagby, D. R. (1995). Using cognitive theory to explain entrepreneurial risk-taking: Challenging conventional wisdom. Journal of Business Venturing, 10(6), 425-438.

Pan, B., \& Fesenmaier, D. R. (2006). Online information search: Vacation planning process. Annals of Tourism Research, 33(3), 809-832.

Peattie, S., Clarke, P., \& Peattie, K. (2005). Risk and responsibility in tourism: Promoting sun-safety. Tourism Management, 26(3), 399-408.

Pizam, A., Jeong, G.-H., Reichel, A., van Boemmel, H., Lusson, J. M., Steynberg, L., et al. (2004). The relationship between risk-taking, sensation-seeking, and the tourist behavior of young adults: A cross-cultural study. Journal of Travel Research, 42(3), 251-260. 
Pizam, A., \& Mansfeld, Y. (2006). Chapter 1 - Toward a Theory of Tourism Security Tourism, Security and Safety (pp. 1-27). Boston: Butterworth-Heinemann.

Qu, H., Kim, L. H., \& Im, H. H. (2011). A model of destination branding: Integrating the concepts of the branding and destination image. Tourism Management, 32(3), 465-476.

Reisinger, Y., \& Mavondo, F. (2006). Cultural differences in travel risk perception. Journal of Travel \& Tourism Marketing, 20(1), 13-31.

Rittichainuwat, B. N., \& Chakraborty, G. (2009). Perceived travel risks regarding terrorism and disease: The case of Thailand. Tourism Management, 30(3), 410-418.

Roehl, W. S., \& Fesenmaier, D. R. (1992). Risk perceptions and pleasure travel: An exploratory analysis. Journal of Travel Research, 30(4), 17-26.

Rosch, E. (1978). Principles of categorization. In E. Rosch \& B. B. Lloyd (Eds.), Cognition and categorization (Vol. 1). Hillsdale, NJ: Lawrence Erlbaum Associates.

Saunders, R., Weiler, B., Scherrer, P., \& Zeppel, H. (in press). Best practice principles for communicating safety messages in national parks. Journal of Outdoor Recreation and Tourism.

Seabra, C., Dolnicar, S., Abrantes, J. L., \& Kastenholz, E. (2013). Heterogeneity in risk and safety perceptions of international tourists. Tourism Management, 36, 502-510.

Sönmez, S. F., Apostolopoulos, Y., \& Tarlow, P. (1999). Tourism in crisis: Managing the effects of terrorism. Journal of Travel Research, 38(1), 13-18.

Sönmez, S. F., \& Graefe, A. R. (1998). Determining future travel behavior from past travel experience and perceptions of risk and safety. Journal of Travel Research, 37(2), 171-177.

Tsaur, S.-H., Tzeng, G.-H., \& Wang, K.-C. (1997). Evaluating tourist risks from fuzzy perspectives. Annals of Tourism Research, 24(4), 796-812.

Tse, A. C. B. (1999). Factors affecting consumer perceptions on product safety. European Journal of Marketing, 33(9/10), 911-925.

Um, S., \& Crompton, J. L. (1992). The roles of perceived inhibitors and facilitators in pleasure travel destination decisions. Journal of Travel Research, 30(3), 18-25.

Wang, C.-J., Tsai, H.-T., \& Tsai, M.-T. (2014). Linking transformational leadership and employee creativity in the hospitality industry: The influences of creative role identity, creative selfefficacy, and job complexity. Tourism Management, 40, 79-89.

Wang, S., \& Xu, H. (2015). Influence of place-based senses of distinctiveness, continuity, self-esteem and self-efficacy on residents' attitudes toward tourism. Tourism Management, 47, 241-250.

Wang, Y., \& Fesenmaier, D. R. (2003). Assessing motivation of contribution in online communities: An empirical investigation of an online travel community. Electronic markets, 13(1), 33-45.

Weber, K. (2001). Outdoor adventure tourism: A review of research approaches. Annals of Tourism Research, 28(2), 360-377.

Williams, A. M., \& Baláž, V. (2013). Tourism, risk tolerance and competences: Travel organization and tourism hazards. Tourism Management, 35, 209-221.

Williams, A. M., \& Baláž, V. (2015). Tourism risk and uncertainty: Theoretical reflections. Journal of Travel Research, 54(3), 271-287.

Wolff, K., \& Larsen, S. (2014). Can terrorism make us feel safer? Risk perceptions and worries before and after the July 22nd attacks. Annals of Tourism Research, 44, 200-209.

World Tourism Organization. (2018). UNWTO World Tourism Barometer. Retrieved 8/8/2018, from World Bank:

http://data.worldbank.org/indicator/ST.INT.DPRT?locations=US\&year high desc=true

Yoo, C. W., Goo, J., Huang, C. D., Nam, K., \& Woo, M. (2017). Improving travel decision support satisfaction with smart tourism technologies: A framework of tourist elaboration likelihood and self-efficacy. Technological Forecasting and Social Change, 123, 330-341.

Yüksel, A., \& Yüksel, F. (2007). Shopping risk perceptions: Effects on tourists' emotions, satisfaction and expressed loyalty intentions. Tourism Management, 28(3), 703-713. 
Zeugner-Roth, K. P., \& Žabkar, V. (2015). Bridging the gap between country and destination image: Assessing common facets and their predictive validity. Journal of Business Research, 68(9), 1844-1853.

Zuckerman, A., \& Chaiken, S. (1998). A heuristic-systematic processing analysis of the effectiveness of product warning labels. Psychology \& Marketing, 15(7), 621-642. 


\section{TABLES}

Table 1

Analysis of covariance results for predicting visit intention.

\begin{tabular}{lccc} 
Source & $d . f$. & MS & $F$-value \\
\hline Covariates & & & \\
$\quad$ Age & 1 & 1.232 & 0.826 \\
$\quad$ Gender & 1 & 0.213 & 0.143 \\
$\quad$ Income & 1 & 0.037 & 0.025 \\
$\quad$ Education & 1 & 0.059 & 0.039 \\
$\quad$ Frequency traveling & 1 & 15.49 & $10.381^{* *}$ \\
Main Effects & & & \\
$\quad$ Presence safety message (A) & 1 & 13.676 & $9.166^{* *}$ \\
$\quad$ Risk propensity groups (B) & 1 & 7.14 & $4.786^{*}$ \\
$\quad$ Self-efficacy groups (C) & 1 & 27.988 & $18.758^{* * *}$ \\
Interaction & & & \\
$\quad$ A x B & 1 & 6.14 & $4.115^{*}$ \\
$\quad$ A x C & 1 & 4.808 & $3.222+$ \\
Error & 301 & 1.492 & \\
Total & 312 & & \\
\hline$* p<.05 ; * * p<.01 ; * * * p<.001$ & & & \\
$\quad+p<.1$ & & &
\end{tabular}




\section{FIGURES}

Fig. 1. Interaction between risk propensity and experimental conditions on visit intention.

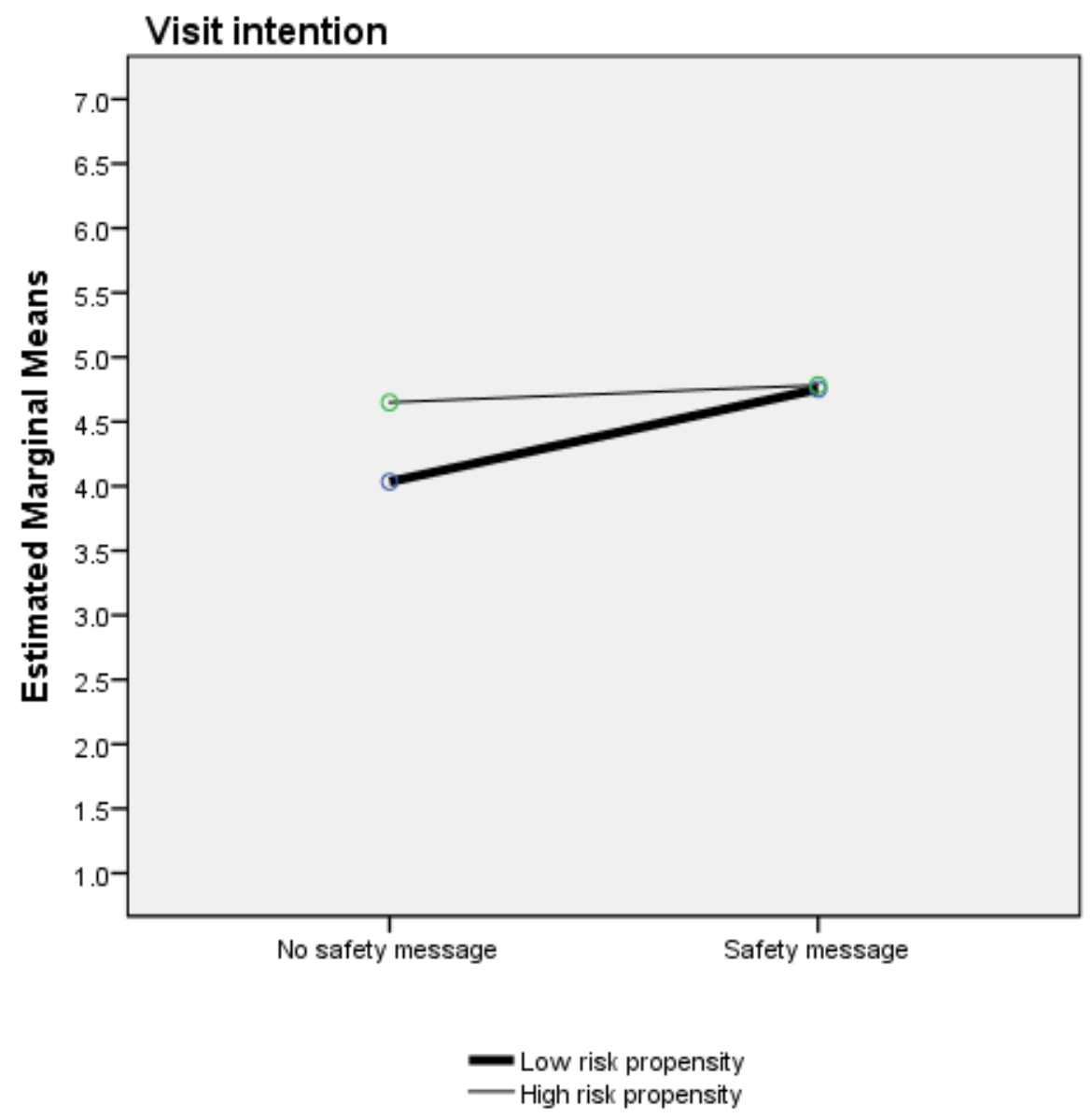


Fig. 2. Interaction between self-efficacy and experimental conditions on visit intention.

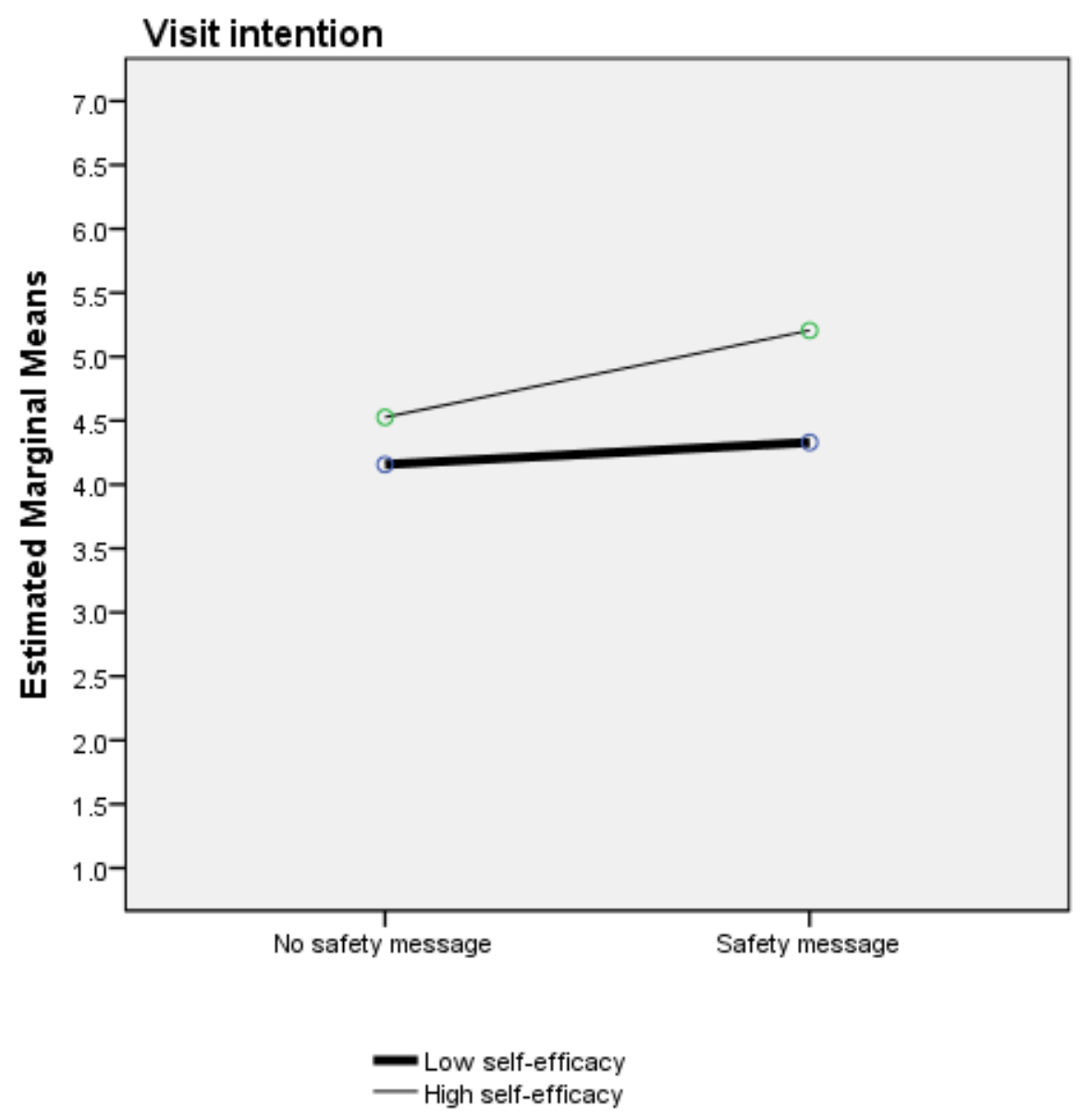




\section{Appendix A}

Fig. 3. Exclusion of safety messages (a color version is shown in the survey).

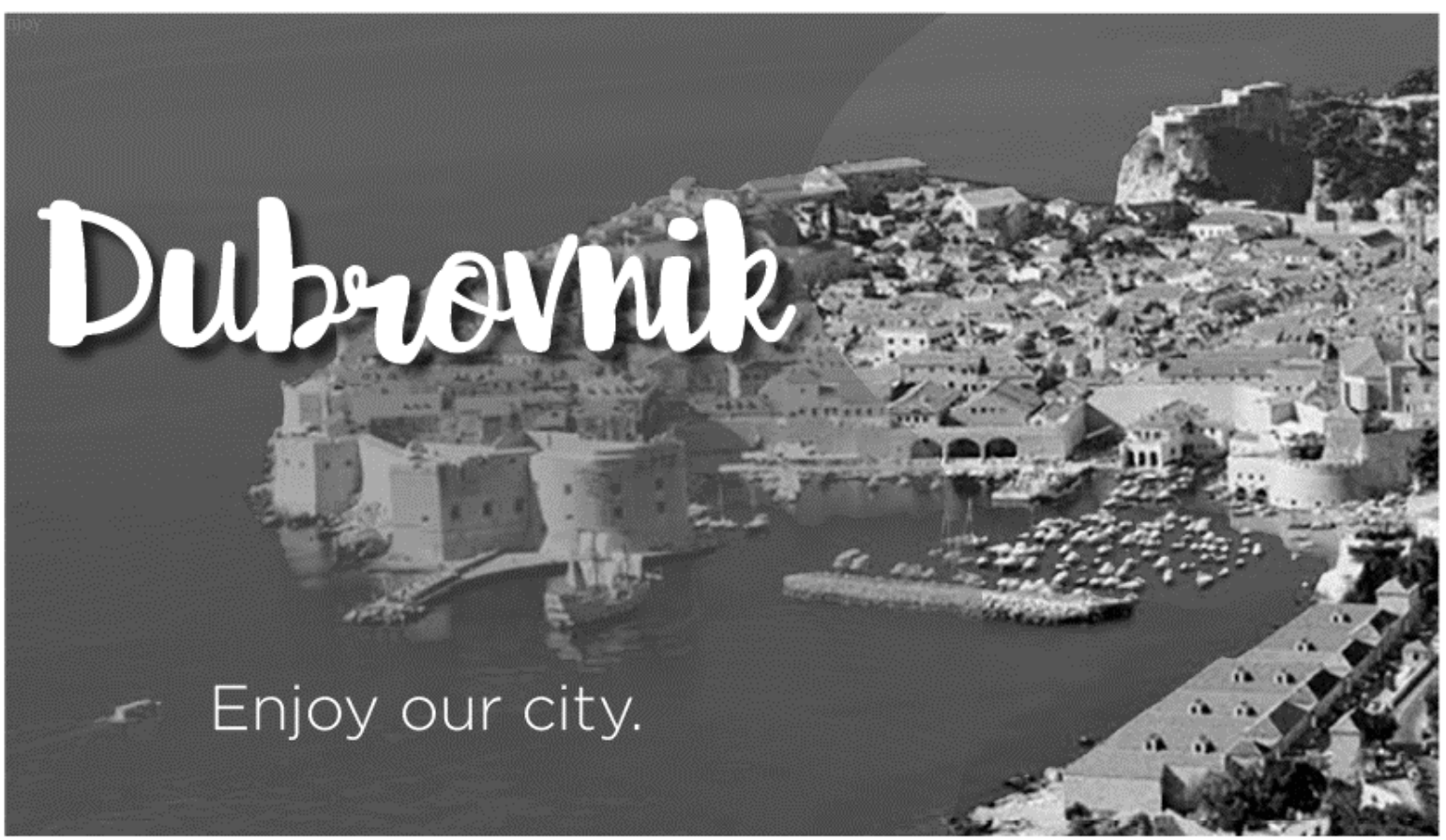


Fig. 4. Inclusion of safety messages (a color version is shown in the survey).

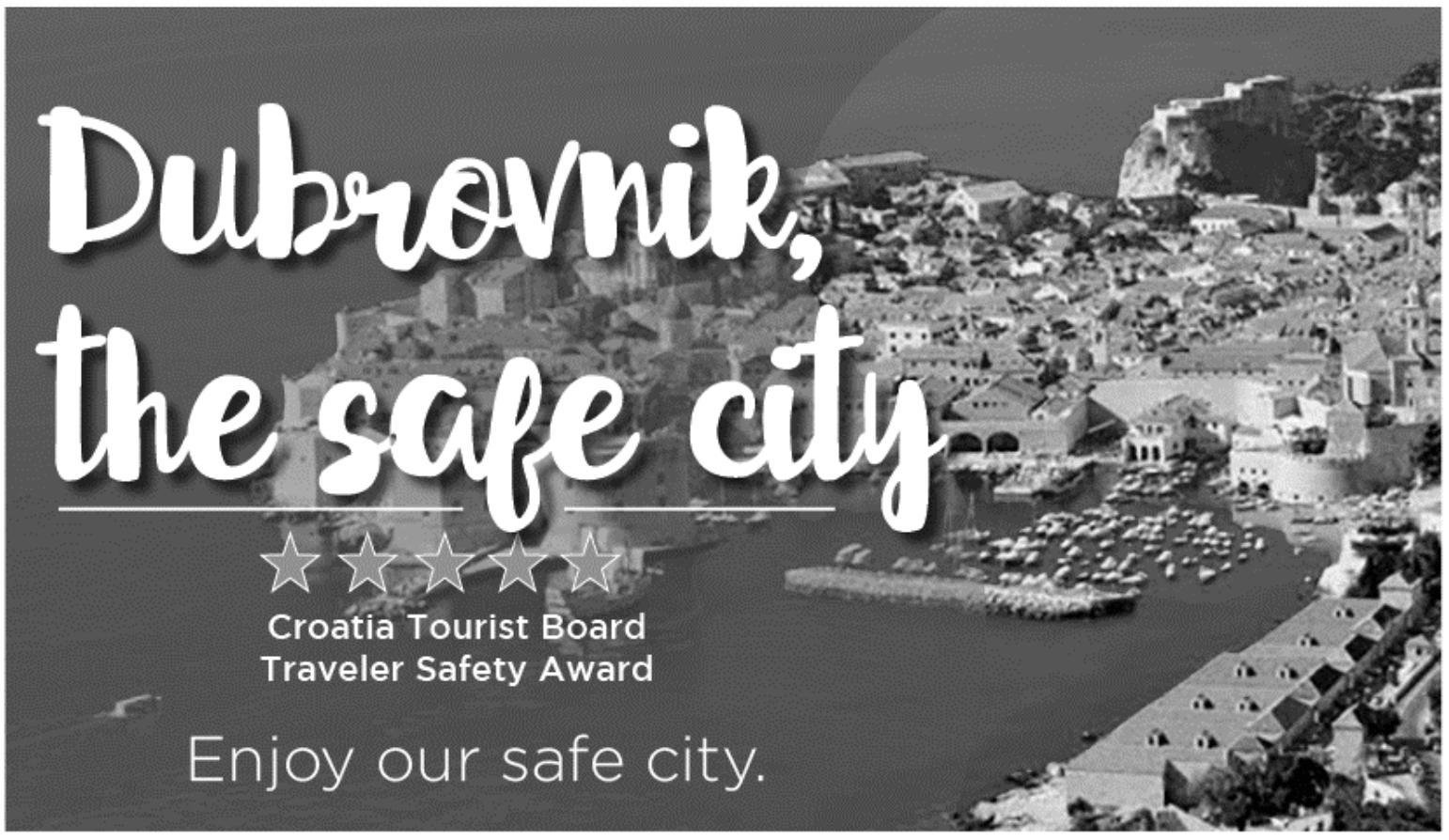




\section{Appendix B}

Constructs and items: Mean, standard deviation, skew, and kurtosis

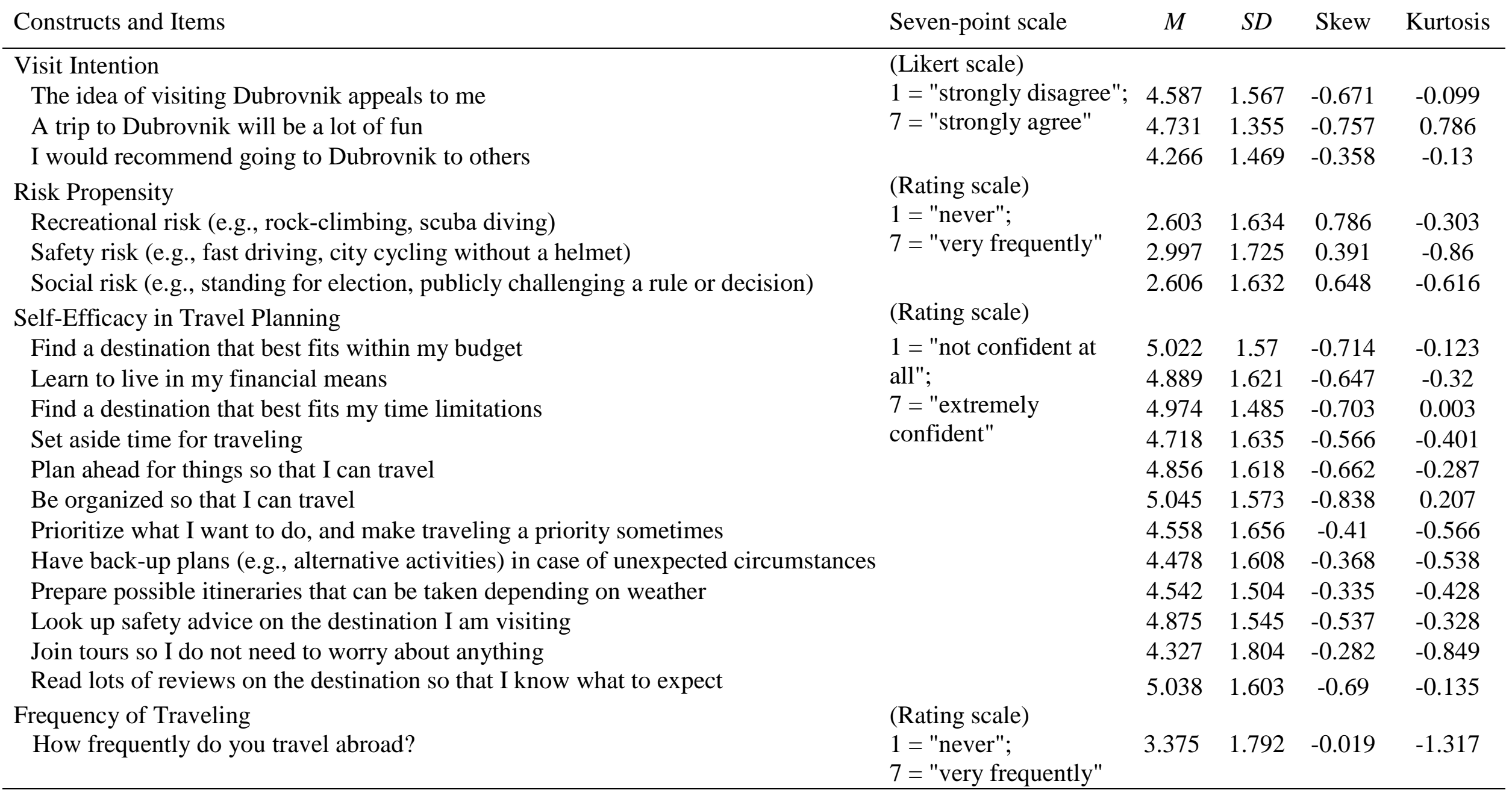


